\title{
Disease Modifying Agents for Multiple Sclerosis
}

\author{
Olga Hilas*,1,2, Priti N. Patel ${ }^{3}$ and Sum Lam ${ }^{3,4}$ \\ ${ }^{1}$ St. John's University College of Pharmacy and Allied Health Professions, Queens, NY; ${ }^{2}$ Department of Pharmacy. New \\ York-Presbyterian Hospital, Weill Cornell Medical Center, New York, USA \\ ${ }^{3}$ Department of Clinical Pharmacy Practice, St. John's University, College of Pharmacy and Allied Health Professions, \\ Queens, NY, USA \\ ${ }^{4}$ Divisions of Geriatric Medicine \& Pharmacy, Winthrop University Hospital, Mineola, New York, USA
}

\begin{abstract}
Objective: To summarize major clinical trials which evaluate the efficacy and safety data of approved disease modifying agents for the treatment of various types of multiple sclerosis.

Data Sources: A MEDLINE (1966 to August 2008) search of clinical trials using the terms multiple sclerosis, interferon, glatiramer, mitoxantrone and natalizumab was performed. A manual bibliographic search was also conducted. Englishlanguage articles identified from the searches were evaluated. New agents under investigation in phase 3 clinical trials were identified using www.clinicaltrials.gov.

Study Selection \& Data Extraction: Relevant information was identified and selected based on clinical relevance and evidence-based strength. Prescribing information leaflets were used to provide usual dosage, contraindications, precautions, monitoring parameters and other relevant drug-specific information.

Data Synthesis: Interferon beta products are more efficacious for the treatment of relapsing-remitting multiple sclerosis. Interferon beta 1-b also delayed the time to diagnosis of definite multiple sclerosis and reduced brain lesion burden in patients with clinical isolated syndrome. Glatiramer and natalizumab have both established efficacy in relapsing forms of multiple sclerosis; whereas mitoxantrone is more commonly used in patients with advanced disease. There are limited data the comparative efficacy among different disease modifying agents. New agents currently under investigation have showed promising results and may offer more treatment options in the future.

Conclusions: MS is a complex and devastating disease with challenging treatment considerations and approaches. Interferon beta products continue to be the mainstay of therapy in many patients, however, other treatments are proving to be at least as effective in the management of various types of MS. Newer compounds are being developed and studied with much anticipation and promise for the clinical management of the disease.
\end{abstract}

Keywords: Multiple sclerosis, disease modifying therapy, immune modulators, interferon beta, glatiramer, mitoxantrone, natalizumab.

\section{INTRODUCTION}

Multiple sclerosis (MS) is a debilitating condition that affects approximately 400,000 Americans and 2.5 million people worldwide [1-3]. It is usually diagnosed between age 20 and 50, and affects women twice more often than men [1]. Risk factors include geographic location, ethnicity and genetics [2]. Scandinavian descent and persons who live further away from the equator are more likely to be inflicted $[4,5]$. Although the familial recurrence rate of MS is low $(\sim 5 \%)$, a positive family history can increase the risk by 30 to 50 times $[2,6]$. About $15 \%$ of patients with MS have at

*Address correspondence to this author at the St. John's University College of Pharmacy and Allied Health Professions, Queens, NY; Clinical Coordinator of Internal Medicine/Geriatrics, Department of Pharmacy. New YorkPresbyterian Hospital, Weill Cornell Medical Center, New York, USA; Tel: (718) 990-1887; Fax: (718) 990-1986;

E-mail: hilaso@stjohns.edu least one additional relative suffering from the disease $[2,6]$. Concordance data shows a higher prevalence of MS among monozygotic (25\%) than among dizygotic twins (3-5\%) [5, 7]. Disability due to MS can accumulate and reduce life span by 6 to 7 years and patients survive for about 35-40 years from the time of diagnosis [2, 8]. This article provides an overview of MS, as well as a review of the agents commonly used to manage its symptoms and progression.

\section{PATHOPHYSIOLOGY AND ETIOLOGY}

The exact causes of MS are unclear. Autoimmune and microbial etiologies have been proposed to explain the pathophysiology of MS. In the autoimmune etiology theory, a patient's own immune system attacks against myelin or oligodendrocyte antigens $[1,2,9]$. This leads to the stripping of myelin sheath which is a protein-lipoid substance surrounding the neuronal axons. Myelin sheath insulates, protects, and helps to conduct nerve impulses. Demyelination, together with inflammatory responses, leads to the formation of characteristic lesions in the central nervous system (CNS). 
This destructive process leads to axonal damage even early in the disease and may result in neurologic symptoms, which typically reflect the affected area of the CNS $[1,2,9]$.

In the microbial etiology theory, bacteria or viruses are responsible for the pathogenesis of MS. Suspected organisms include varicella zoster, rubella, Epstein-Barr, human herpes virus 6 , mycoplasma, rabies virus, canine distemper virus, retrovirus, mumps, measles, Chlamydia pneumoniae, and others. Nevertheless, no one particular pathogen has been fully established as a causal agent for MS symptoms [1, 2, 912].

Environmental factors may also contribute to the pathogenesis [13]. MS is more prevalent in countries with moderate or cool climate, areas with greater distances from the equator in both the northern and southern hemispheres [1]. Interestingly, the environmental influence is more important between the ages of 10 and 15 years [13, 14].

\section{CLINICAL MANIFESTATIONS}

MS has a variable clinical presentation with its clinical course or disease progression related to the type of MS [2, 15]. The disease consists of four distinct types or stages: (1) relapsing-remitting MS (RRMS); (2) secondary progressive MS (SPMS); (3) primary progressive MS (PPMS); and progressive-relapsing MS (PRMS) [2, 15, 16, 20].

RRMS is the most common type, affecting approximately 80 to $85 \%$ of patients beginning in their second or third decade of life and clinically manifesting in the third or fourth decade $[2,15,17]$. Women are twice as likely to present with this type of MS [2]. Signs and symptoms usually present over a course of days, typically stabilizing and spontaneously resolving. Disability and CNS dysfunction may present and progress after relapses, and during times of remission [2, 15]. Initial symptoms include sensory, visual, balance and gait disturbances, limb weakness, neurogenic bladder and bowel problems. Temporal fatigue and increases in body temperature have also been reported. In addition, cognitive impairment, depression, emotional lability, dysarthria, dysphagia, vertigo, progressive quadriparesis and sensory loss, ataxic tremors, pain, sexual dysfunction, spasticity, and other apparent CNS problems may arise [2].

An estimated 50\% of RRMS patients over a period of 10 years [18] and about $90 \%$ over 25 years will experience a stage transition to SPMS [16]. SPMS is characterized by a gradual and worsening disability with or without the presence of superimposed relapses [17, 19]. Exacerbations may or may not be seen during the secondary progressive stage [20].

PPMS affects approximately $10-20 \%$ of patients and carries the worst prognosis $[2,17]$. The incidence has been reported to be similar among men and women [2]. It is characterized by a gradual and progressive course in which patients experience continuous worsening in disease from onset with no exacerbations or remission periods $[2,20]$. Initial presentation includes a slow progressive myelopathy of the legs. Quadraparesis, cognitive decline, visual loss, brain-stem syndromes, and dysfunction of bowel, bladder, and reproductive systems may also occur [2].

A fourth and unusual type, referred to as progressiverelapsing MS (PRMS), has also been introduced as a pro- gressive disease from onset with clear, acute and superimposed relapses with or without recovery [20]. However, one study found that there was no differentiation between primary progressive and progressive-relapsing based on clinical characteristics and progression of disability [21].

All types of MS can cause significant disability [15]. Although it is difficult to predict the progressive course and development of disability [17], poor prognostic factors have been described: male gender, older age at onset, motor symptoms or cerebellar signs at onset, short interval and incomplete recovery between the initial and subsequent attack, high relapse rate early on in disease, early disability, moderate disability within 5 years and high lesion load revealed on early magnetic resonance imaging (MRI) of the brain [16, $18,22,23]$.

\section{DIAGNOSIS}

Currently, no specific diagnostic test is available for MS. Therefore, appropriate diagnosis depends on thorough history and examination and objective evidence of CNS lesions scattered in space and time [24, 25]. An MRI is utilized to support the clinical diagnosis, confirm dissemination in space, and rule out other potential causes such as metabolic, vascular, psychiatric, genetic, autoimmune, neuropathic, neoplastic and other disorders [2]. It is the most sensitive and specific technique for detecting MS lesions and quantifying their progression over time [26]. Typical findings include multifocal lesions of various ages primarily involving the periventricular white matter, brain stem, cerebellum, and spinal cord white matter. In addition, the presence of gadolinium-enhanced lesions indicates inflammatory demyelination [2].

Cerebrospinal fluid (CSF) analysis and visual evoked potentials (VEP) are also used to further assist in the diagnosis. CSF analysis provides information on inflammatory and immunologic disturbances, while VEP provide physiologic evidence of optic nerve dysfunction. Somatosensory evoked potentials (SEP) detect spinal cord dysfunction, and can provide diagnostic support when used along with spinal MRI [2, 24].

In 2000, the International Panel on the Diagnosis of MS developed the McDonald Criteria [24]. Core features of these diagnostic criteria include: emphasis on objective clinical findings; dependence on evidence of dissemination of lesions in time and space; use of supportive and confirmatory paraclinical examination; focus on specificity rather than sensitivity; and elimination of better explanations for a diagnosis [24, 27]. In the 2005, its revisions called for a particular focus on MRI criteria for dissemination of lesions in time, incorporation of spinal cord lesions into the imaging requirements, and establishing a diagnosis of PPMS by concentrating on clinical and imaging evidence and placing less emphasis on CSF findings [27].

\section{APPROVED DISEASE MODIFYING AGENTS}

\section{Interferon $\beta$}

Interferon $\beta$ (IFN $\beta$ ) is produced by fibroblasts and has antiviral, antiproliferative, and immunomodulatory effects [28]. Currently, there are two types of IFN $\beta$ available: IFN $\beta$ $1 \mathrm{a}$ and IFN $\beta-1 \mathrm{~b}$ (Table 1). IFN $\beta-1 \mathrm{a}$ is identical to natural IFN $\beta$, while IFN $\beta-1 b$ has a serine substitution for cysteine at 
position 17 [29]. Also of note, IFN $\beta$-1a is glycosylated, while IFN $\beta-1 b$ is not [29].

\section{Interferon $\boldsymbol{\beta}$-1a}

IFN $\beta-1 \mathrm{a}$ is available as two different formulations: a once weekly intramuscular (IM) injection (Avonex ${ }^{\circledR}$ ) and a three times weekly (TIW) subcutaneous (SC) injection (Rebif $\left.^{\circledR}\right)$. Intramuscular IFN $\beta-1$ a was approved by the FDA in May 1996 following two clinical trials that demonstrated efficacy. In one double-blind, placebo-controlled study, patients with RRMS were randomized to receive either IFN $\beta$ 1a $30 \mathrm{mcg}$ IM once weekly $(n=158)$ or placebo $(n=143)$ for up to 104 weeks [30]. The primary outcome was the time to

Table 1. FDA Approved Disease-Modifying Agents for the Management of Multiple Sclerosis

\begin{tabular}{|c|c|c|c|c|}
\hline Drug & Mechanism of Action & $\begin{array}{l}\text { Approved } \\
\text { Indication }\end{array}$ & Usual Dosage & Notes \\
\hline $\begin{array}{l}\text { Interferon beta-1a } \\
\left(\text { Avonex }^{\circledR}\right)\end{array}$ & $\begin{array}{l}\text { Anti-proliferation, immunomodula- } \\
\text { tion }\end{array}$ & RRMS & $30 \mathrm{mcg}$ SC once weekly & \\
\hline $\begin{array}{l}\text { Interferon beta- 1a } \\
\left.\text { (Rebif }^{\oplus}\right)\end{array}$ & $\begin{array}{l}\text { Anti-proliferation, immunomodula- } \\
\text { tion }\end{array}$ & RRMS & $\begin{array}{l}20 \% \text { of target dose initially, titrate } \\
\text { to } 22 \text { mcg or } 44 \text { mcg IM TIW over } \\
4 \text { weeks }\end{array}$ & $\begin{array}{l}\text { Administer on the same } \\
\text { days each week, at least } 48 \\
\text { hours apart }\end{array}$ \\
\hline $\begin{array}{l}\text { Interferon beta-1b } \\
\left(\text { Betaseron }^{\circledR}\right)\end{array}$ & $\begin{array}{l}\text { Anti-proliferation, immunomodula- } \\
\text { tion }\end{array}$ & $\begin{array}{l}\text { RRMS, CIS with } \\
\text { MRI features } \\
\text { consistent with } \\
\text { MS }\end{array}$ & $\begin{array}{l}0.0625 \mathrm{mg} \text { SC QOD initially; } \\
\text { increase to } 0.25 \mathrm{mg} \text { QOD over } 6 \\
\text { weeks }\end{array}$ & $\begin{array}{l}\text { CBC and LFT at baseline } \\
\text { and } 1,3,6 \text { months thereafter; } \\
\text { TFT every } 6 \text { months in } \\
\text { selected patients }\end{array}$ \\
\hline $\begin{array}{l}\text { Glatiramer (Copax- } \\
\left.\text { one }^{\circledR}\right)\end{array}$ & $\begin{array}{l}\text { Competitive binding with MBP, } \\
\text { cytokine modulation \& inhibition of } \\
\text { free radical }\end{array}$ & RRMS & 20 mg SC daily & $\begin{array}{l}\text { Routine laboratory monitor- } \\
\text { ing is not required }\end{array}$ \\
\hline $\begin{array}{l}\text { Mitoxantrone } \\
\left(\text { Novantrone }^{\circledR}\right)\end{array}$ & $\begin{array}{l}\text { Intercalates into DNA; interferes with } \\
\text { RNA; inhibits topoisomerase II; anti- } \\
\text { proliferation; immunomodulation; } \\
\text { TNF- } \alpha \text { and IL-2 inhibition }\end{array}$ & $\begin{array}{l}\text { SPMS, PRMS, or } \\
\text { worsening RRMS }\end{array}$ & $\begin{array}{l}12 \mathrm{mg} / \mathrm{m}^{2} \text { IV infusion over } 5-15 \\
\text { minutes every } 3 \text { months }\end{array}$ & $\begin{array}{l}\text { Bone marrow suppression } \\
\text { (neuropenia) may occur. } \\
\text { CBC should be monitored } \\
\text { prior to initial dose, before } \\
\text { each subsequent dose, and } \\
\text { after discontinuation of } \\
\text { therapy } \\
\text { Assessment of cardiac func- } \\
\text { tion recommended prior to } \\
\text { initiation, during treatment } \\
\text { and yearly after discontinua- } \\
\text { tion (history, physical ex- } \\
\text { amination, electrocardio- } \\
\text { gram and quantitative } \\
\text { evaluation of left ventricular } \\
\text { ejection fraction via echo- } \\
\text { cardiogram, multi-gated } \\
\text { radionuclide angiography } \\
\text { (MUGA), MRI, etc.) } \\
\text { LFT should be } \\
\text { monitored prior to initial } \\
\text { dose and before each subse- } \\
\text { quent dose } \\
\text { Secondary acute } \\
\text { myelogenous leukemia } \\
\text { (AML) has been reported. } \\
\text { Elevated risk of } 0.25 \% \text { has } \\
\text { been observed }\end{array}$ \\
\hline $\begin{array}{l}\text { Natalizumab } \\
\left.\text { (Tysabri }^{\circledR}\right)\end{array}$ & $\begin{array}{l}\text { Inhibits the adhesion of molecules } \\
\text { onto the surface of immune cells; } \\
\text { potentially inhibits the migration of } \\
\text { immune cells }\end{array}$ & $\begin{array}{l}\text { Monotherapy for } \\
\text { relapsing forms of } \\
\text { MS }\end{array}$ & $\begin{array}{l}\text { 300mg IV infusion over approxi- } \\
\text { mately one hour every } 4 \text { weeks } \\
\text { (data on the efficacy and safety is } \\
\text { limited to two years) }\end{array}$ & $\begin{array}{l}\text { CBC, WBC, LFT (including } \\
\text { bilirubin) should be moni- } \\
\text { tored regularly } \\
\text { Antibody testing upon initia- } \\
\text { tion and at } 3 \text { months (if } \\
\text { persistent antibodies are } \\
\text { suspected) } \\
\text { Hypersensitivity/ anaphy- } \\
\text { laxis may occur within } 2 \\
\text { hours of infusion } \\
\text { Gadolinium-enhanced brain } \\
\text { MRI and CSF analysis for } \\
\text { JC viral DNA are recom- } \\
\text { mended for suspected PML }\end{array}$ \\
\hline
\end{tabular}

MBP = myelin binding proteins; TNF = tumor necrosis factor; IL = interleukin; CIS = clinical isolated syndrome; RRMS = relapsing-remitting multiple scleroris; MRI = magnetic resonance imaging; SPMS = secondary progressive multiple sclerosis; PRMS = progressive relapsing multiple sclerosis; $\mathrm{SC}=$ subcutaneously; QOD = every other day; IV = intravenously; $\mathrm{CBC}=$ complete blood count; $\mathrm{LFT}=$ liver function tests; TFT = thyroid function tests; $\mathrm{CSF}=$ cerebrospinal fluid; $\mathrm{PML}=$ progressive multifocal leukoencephalopathy . 
onset of sustained disease disability, as defined by a decrease from baseline expanded disability status scale (EDSS) scores of at least 1 point for at least 6 months. Other outcomes included the number of exacerbations and brain lesions. Of the patients who completed 104 weeks of the study, 85 received IFN $\beta$ and 87 received placebo. The primary outcome, time to sustained progression of disease disability, was significantly prolonged in the interferon group as compared to the placebo group $(p=0.02)$. The number of exacerbations were significantly lower in the interferon group $(0.82$ vs 0.67 per year per patient; $\mathrm{p}=0.04$ ) when looking at all patients. The difference was more pronounced in the patients who completed 104 weeks of treatment, where the number of exacerbations per year per patient was 0.90 in the placebo group and 0.61 in the IFN group $(\mathrm{p}=0.002)$. At the end of one year, $29.9 \%$ in the IFN group and $42.3 \%$ in the placebo group $(p=0.05)$ had positive MRI scans. At the end of year two, the percentages of positive MRI scans were similar: $28.9 \%$ vs $42.7 \%$, respectively $(\mathrm{p}=0.02)$. Overall, IFN was well-tolerated. The adverse events that occurred more often in the IFN group included flu-like symptoms, muscle aches, fever, and chills.

The second study on IM IFN $\beta$-1a was a randomized, double-blind, placebo-controlled, multicenter trial in patients who had recently experienced their first demyelinating event involving the optic nerve, brainstem, cerebellum, or spinal cord, and also had to have subclinical lesions on MRI [31]. Patients first received a regimen of methylprednisolone $1 \mathrm{~g}$ IV for 3 days, then prednisone $1 \mathrm{mg} / \mathrm{kg}$ orally for 11 days, then a 4 day period of steroid taper. Patients were then randomized to receive either IFN $\beta-1$ a $30 \mathrm{mcg}$ IM once weekly $(n=193)$ or placebo $(n=190)$ for 3 years. Cumulative probability of developing clinically confirmed MS during the 3 years was significantly decreased in the IFN $\beta$ group (rate ratio 0.56 ; $95 \% \mathrm{CI} 0.38-0.81 ; \mathrm{p}=0.002$ ). On MRI, the number of new or enlarging lesions was significantly lower in the IFN $\beta$ group at months $6(\mathrm{p}=0.001), 12(\mathrm{p}<0.001)$, and 18 $(p<0.001)$. The volume of lesions seen on MRI also significantly decreased in the IFN group at $6(\mathrm{p}<0.001), 12$ $(\mathrm{p}=0.004)$, and 18 months $(\mathrm{p}<0.001)$. Influenza-like symptoms and depression occurred statistically more often in the IFN $\beta$ group.

Subcutaneous IFN $\beta$-1a was approved by the FDA in May 2002 following the completion of two clinical trials: Prevention of Relapses and Disability by IFN $\beta-1$ a Subcutaneously in Multiple Sclerosis (PRISMS-2) and Evidence of Interferon Dose-Response: European North American Comparative Efficacy (EVIDENCE). The PRISMS-2 was a multicenter, double-blind, placebo-controlled trial enrolling 560 patients with RRMS [32]. Patients were randomly assigned to receive SC IFN $\beta$-1a $22 \mathrm{mcg}, 44 \mathrm{mcg}$, or placebo TIW for 2 years. Ninety percent of patients completed this study. The mean number of relapses decreased significantly in the IFN groups: 2.56 placebo, 1.82 IFN $22 \mathrm{mcg}$ ( $\mathrm{p}<0.005 \mathrm{vs}$ placebo), and 1.73 IFN $\beta 44 \mathrm{mcg}$ ( $\mathrm{p}<0.005$ vs placebo). Time to progression was longer in both IFN $\beta$ groups compared to placebo $(\mathrm{p}<0.05)$. The percentage of relapse-free patients over 2 years was $27 \%$ in the $22 \mathrm{mcg}$ group ( $<<0.05$ vs placebo), $32 \%$ in the $44 \mathrm{mcg}$ group ( $<<0.005$ vs placebo), and $16 \%$ in the placebo group. Statistically significant responses were seen in the IFN $\beta$ groups for decreased positive MRI scans and other endpoints. Overall, IFN $\beta$-1a was well-tolerated. Injection-site reactions, lymphopenia, increased liver function test
(LFT), and granulocytopenia were reported more often among the IFN groups.

Results of a 2 year follow up study (PRISMS-4) were later published [33]. During years 3 and 4 of the study, patients originally receiving placebo were randomized in a double-blind fashion to receive IFN $\beta-1$ a $22 \mathrm{mcg}$ TIW or $44 \mathrm{mcg}$ TIW; data for this group was pooled as the "crossover" group. Patients originally receiving either dose of IFN $\beta$ continued that dose through years 3 and 4 . Results showed that patients who received IFN $\beta$-1a for the entire 4 years had fewer relapses per year $(22 \mathrm{mcg}, 0.80$ per year; $44 \mathrm{mcg}, 0.72$ per year) than patients who received 2 years of placebo and 2 years of IFN $\beta$ (1.02 per year).

The EVIDENCE study was an active-controlled, multicenter trial that compared three times weekly SC IFN $\beta$-1a with once weekly IM IFN $\beta-1$ a $\left(\right.$ Avonex ${ }^{\circledR}$ ) for 2 years in patients with RRMS [34]. Patients were randomly assigned to receive either IFN $\beta$-1a SC 44 mcg TIW $(n=33)$ or IFN $\beta-1$ a IM $30 \mathrm{mcg}$ once weekly $(\mathrm{n}=388)$. At the end of 2 years, $75 \%$ in the SC group and $63 \%$ in the IM group were relapse-free (OR 1.9; 95\%CI 1.3-2.6; $\mathrm{p}=0.0005)$. Patients in the SC group had fewer lesions on MRI than the IM group $(\mathrm{p}<0.0001)$. The time to first relapse was prolonged for the patients in the $\mathrm{SC}$ group as compared to the IM group (HR $0.70 ; 95 \% \mathrm{CI}$ $0.55-0.88 ; \mathrm{p}=0.003)$. Lower relapse rates were seen in the $\mathrm{SC}$ group (0.29 vs. 0.40 relapses/patient; $\mathrm{p}=0.022)$. Adverse events were more common in the SC group than in the IM group, with injection-site reactions, systemic influenza-like symptoms, LFT abnormalities, and white blood cell abnormalities occurring more often.

An extension of the EVIDENCE study was later published in which patients were followed for an average of 32 additional weeks [35]. In this phase of the study, patients originally assigned to receive IM IFN $\beta$-1a were switched to the SC form, while those originally receiving the SC form continued in that group. The primary outcome was the change in relapse rate from pre-transition to post-transition. A total of 223 patients who were originally receiving the IM dose were switched to SC (IM to SC group), and 272 continued their originally SC dose (continuing SC group). Posttransition, the relapse rate per year decreased from 0.64 to 0.32 in the IM to SC group ( $\mathrm{p}<0.001)$, and decreased from 0.46 to 0.34 in the continuing SC group $(p=0.03)$. Patients in the continuing SC group had fewer T2-weighted lesions on MRI after the switch $(p=0.02)$, while the SC continuing group had no change in number of lesions. Patients in the IM to SC group had more adverse events, and more patients in this group stopped treatment due to an adverse event. Injection-site reactions, influenza-like symptoms, LFT abnormalities, and white blood cell abnormalities occurred more often post-transition in the IM to SC group.

Both forms of IFN $\beta-1 \mathrm{a}$ are indicated for the treatment of relapsing forms of MS [36, 37]. The frequency of administration may affect the expression of biologic effect markers, indicating differences in therapeutic efficacy. In a study conducted in 1999, subjects were administered IFN $\beta-1$ a $22 \mathrm{mcg}$ once weekly, $22 \mathrm{mcg}$ TIW, or $66 \mathrm{mcg}$ once weekly. Levels of proinflammatory cytokines including tumor necrosis factor$\alpha$, interferon- $\gamma$, interleukin-1 $\beta$, interleukin-6, and tumor necrosis factor- $\beta$ decreased with the increase in dosing frequency ( $22 \mathrm{mcg}$ once weekly vs. TIW), not by the increase in 
absolute dose (22mcg once weekly vs $66 \mathrm{mcg}$ once weekly) [38].

\section{Interferon $\beta$-1b}

IFN $\beta-1 b$ (Betaseron ${ }^{\circledR}$ ) is the first disease modifying agent approved by the FDA in 1993. It is indicated for RRMS initially, and then also for clinical isolated syndrome (CIS) with MRI features consistent with MS [39].

In a multi-center, double-blind, placebo-controlled trial, IFN $\beta-1 b$ reduced exacerbation rates, severity of exacerbations, and accumulation of MRI abnormalities. There was also an insignificant reduction of disability [40, 41]. In this trial, 372 patients with RRMS were randomized to receive placebo and IFN $\beta-1 b$ (1.6 or 8 MIU SC every other day) for 2 years. IFN $\beta-1 b$ demonstrated dose-dependent efficacy in annual exacerbation rates $(1.27,1.17$ and 0.84 , respectively). More patients receiving IFN $\beta-1 \mathrm{~b}$ remained exacerbation-free (36 vs. 18 placebo; $\mathrm{p}=0.007$ ). IFN $\beta-1 \mathrm{~b}$ also significantly delayed the time to first exacerbation by up to 142 days. Overall, IFN $\beta-1 b$ had a persistent beneficial effect on exacerbation rate for up to 3 years and MRI burden of disease for up to 5 years [42]. Reported side effects include lymphopenia, liver enzyme elevation inflammation at injection site, fever, and myalgia.

The efficacy and safety of IFN $\beta-1 b$ in patients with CIS has been demonstrated in a multi-center, randomized, double-blind, placebo-controlled, 2-year trial involving 468 patients [43]. Enrolled patients experienced a first clinical demyelinating event and at least two clinically silent brain MRI lesions. Treatment with IFN $\beta-1 b$ significantly delayed the time to diagnosis of clinically definite MS by $50 \%$ and McDonald MS by $46 \%$. It also significantly reduced secondary MRI endpoints, including newly active lesions and change in T2 lesion volume. Most common reported side effects were injection site reactions, flu-like syndrome, and headache. Incidence of depression was comparable in both groups (10\% vs. $11 \%)$.

Treatment with IFN $\beta$-1b provided conflicting results in patients with SPMS in two multi-center, randomized, double-blind, placebo-controlled trials [44, 45]. In EU-SPMS trial, IFN $\beta-1 \mathrm{~b}$ significantly delayed the progression of disability in European patients with SPMS. The study was terminated one month early due to a compelling evidence of efficacy. Fewer patients receiving IFN $\beta-1 b$ had confirmed disease progression (39\% vs. 50\%, p =0.0048). Overall, treatment with IFN $\beta$-1b delayed progression for 9-12 months (OR $0.65 ; 95 \%$ CI $0.52-0.83$ ). This beneficial effect was seen in patients with superimposed relapses and those with only progressive deterioration without relapses. IFN $\beta-1 b$ also provided beneficial effects on relapse rate, relapse severity, MRI variables and time to becoming wheelchairbound in this 3-year study [44]. The most common reported side effects were flu syndrome, injection site inflammation, injection site reaction, fever, and hypertonia.

Unfortunately, this efficacy was not reproducible in a similar study involving North Americans (NA-SPMS trial) [45] that enrolled 939 subjects with SPMS, but was halted approximately 3 months early due to a lack of efficacy. Although IFN $\beta-1 b$ improved clinical relapses and MRI variables, it did not delay the time to confirmed progression of disability [45].
There are no clear explanations for the contrasting results seen in EU-SPMS [44] and NA-SPMS [45] trials, but differences in patient baseline characteristics may have played an important role [46]. Evidences suggested that patients with ongoing inflammatory activity, as evidenced by pronounced disability progression and ongoing relapses, may benefit more from IFN $\beta-1 b$ therapy [47]. It has been speculated that subjects in the EU-SPMS trial were more subject to treatment benefit compared to those in the NA-SPMS trial. The pooled analysis of both trials showed that treatment with IFN $\beta-1 \mathrm{~b}$ provided a $20 \%$ risk reduction in EDSS progression confirmed at 6 months $(\mathrm{p}=0.008)$. Higher risk reduction (30\% to $40 \%$ ) was seen in patients with at least one relapse or change in EDSS by $>1$ in the 2 years prior to study entry [47].

Even though all IFN $\beta$ s induce neutralizing antibodies, IFN $\beta-1$ a seems to be less immunogenic that IFN $\beta-1 b$, possibly due to its glycosylation $[29,48,49]$. In one study conducted in 2006, IM IFN $\beta$-1a induced neutralizing antibodies at a lower rate $(5 \% ; \mathrm{p}<0.0001)$ than SC IFN $\beta-1 \mathrm{a}(29 \%)$ and interferon $\beta-1 b(31 \%)$ [49]. The frequency of binding antibodies followed the same pattern. However, in the subgroup of patients testing positive for neutralizing antibodies, more patients receiving IFN $\beta-1 \mathrm{a}$ had high titers compared to patients receiving IFN $\beta-1 b(p=0.04)$. This may be the reason that many patients who develop neutralizing antibodies to IFN $\beta-1 \mathrm{~b}$ eventually return to negative neutralizing antibody titers, since higher antibody levels indicate that the antibodies will persist [50]. The IFN $\beta$ s also differ in the extent of liver injury they can cause. A retrospective chart review published in 2004 evaluated aminotransferase levels in 835 patients receiving the three IFN $\beta$ s [51]. The authors concluded that SC IFN $\beta-1 b$ and IFN $\beta-1$ a led to similar elevations of aminotransferase levels, and these were higher than the levels caused by IM IFN $\beta-1$ a.

\section{Glatiramer}

Glatiramer, or copolymer-1 (Copaxone $^{\circledR}$ ) is the acetate salt of a random mixture of synthetic polypeptides composed of L-glutamic acid, L-lysine, L-tyrosine, and L-alanine (Table 1) [52]. It reduces relapses and MRI findings in patients with RRMS [53-56]. In a double-blind, randomized, placebo-controlled 2-year pilot trial that involved 48 patients, glatiramer reduced relapse rate by about 4-fold ( 0.6 vs 2.7 placebo) [54]. Significantly more patients receiving glatiramer remained exacerbation-free at the end of the study (56\% vs. 26\%). Similar results were noted in a double-blind, placebo-controlled, 2-year, phase 3 trial in 251 patients with RRMS [55]. Glatiramer significantly reduced annualized relapse rate by $29 \%(0.59 v s .0 .84 ; \mathrm{p}=0.007)$ with a more profound benefit in subjects with lower EDSS scores of 0 to 2. Nevertheless, glatiramer did not provide benefit in sustained disability progression, defined as a 1.0 point or greater increase in EDSS maintained for 90 days. Drug-related side effects were injection-site reactions (90\% vs. 59\% placebo) and transient self-limiting systematic reactions, characterized by flushing, chest pain, palpitation, anxiety and dyspnea $(15 \%$ vs. $3 \%)$. In a randomized, placebo-controlled extension trial [56], glatiramer provided similar benefit in relapse rate reduction (32\%), and demonstrated benefit on disability progression, defined as worsening by 1.5 or greater on the EDSS $(p=0.001)$. Local injection site reactions occurred 
more commonly in the glatiramer group (66\% vs. $37 \%$ placebo). Immediate systemic reactions were noted with glatiramer use (1\%\% vs. $3.2 \%$ placebo) [56].

Follow-up analyses compared the neurologic status of subjects who remained on glatiramer therapy with those who withdrew from therapy in a 10-year period [57]. Results showed that more patients who remained on glatiramer therapy had stable or improved EDSS scores (68\% vs. 28\%). Still, glatiramer was associated with injection site reactiosn (erythema, pain, mass, edema) and immedidate postinjection reaction (vasodilation, chest pain, palpitation, tachycardia or dyspnea) [57]. Unlike interferons, glatiramer is not associated with flu-like reactions or depression and does not seem to worsen headaches [58, 59]. Glatiramer is a Category B drug but use during pregnancy and breastfeeding is not recommended [52].

Glatiramer has also reduced MRI-measured disease activity and burden among RRMS patients in a randomized, placebo-controlled, 9-month study that involved 239 patients [60]. The glatiramer group had a significant reduction in the total number of enhancing lesion In another study, glatiramer significantly reduced the likelihood of new T2 lesions after 7 and 8 months, and provided a favorable effect on tissue disruption in MS lesions [61]. In addition, a small study showed that glatiramer may be an option for continuing disease modification in patients with RRMS who received prior treatment with mitoxantrone [62], or IFN $\beta$ treatments [63, 64].

A randomized, placebo-controlled, 3-year (PROMISE) trial was planned to evaluate the effect of glatiramer in delaying time to confirmed disease progression in 943 patients with PPMS. Unfortunately, it was halted early due to significant dropout of patients $(26.4 \%)$ and marked slower annual progression rate in the placebo group $(16.1 \%$ compared to an expected rate of 50\%) [65].

\section{Mitoxantrone}

Mitoxantrone was approved by the FDA in October 2000 , and is indicated for the reduction of neurologic disability and/or frequency of clinical relapses in patients with SPMS, PRMS, or worsening RRMS (Table 1). The approval of mitoxantrone was based on two phase III clinical trials. The first study was a multicenter, double-blind, placebocontrolled, trial conducted in patients with SPMS or PRMS $[66,67]$ A total of 194 patients were enrolled and 188 patients were included in an intent-to-treat analysis at 24 months. Patients were randomized to receive either mitoxantrone $5 \mathrm{mg} / \mathrm{m}^{2}$, mitoxantrone $12 \mathrm{mg} / \mathrm{m}^{2}$ or placebo IV every 3 months for 24 months.

In comparing mitoxantrone $5 \mathrm{mg} / \mathrm{m}^{2}$, mitoxantrone $12 \mathrm{mg} / \mathrm{m}^{2}$ or placebo, the mean EDSS changes was $0.23,0.13$ and 0.23 , mean ambulation index changes was $0.41,0.30$ and 0.77 , mean number of relapses treated with corticosteroids was $0.73,0.40$ and 1.20 , median months to first relapse requiring corticosteroids was 6.9, 20.4, 6.7, and mean standardization neurological status change was $0.38,1.07,0.77$, respectively (all p values significant).

In regards to the subset of patients undergoing MRI assessment, the number of patients with new gadoliniumenhancing lesions was $11 \%, 0 \%$ and $18 \%$ in the mitoxan- trone $5 \mathrm{mg} / \mathrm{m}^{2}$, mitoxantrone $12 \mathrm{mg} / \mathrm{m}^{2}$ and placebo groups, respectively $(p=0.022)$. The mean number of patients in which a change in the number of $\mathrm{T} 2$-weighted lesions were 34,28 and 32, respectively.

Mitoxantrone was most frequently reported to cause mild or moderate nausea, urinary tract infections, menstrual disorders including amenorrhea, and mild alopecia, compared to the placebo group. Approximately $9.7 \%$ (6/60) of patients in the mitoxantrone $12 \mathrm{mg} / \mathrm{m}^{2}$ group discontinued treatment due to the occurrences of leukopenia, depression, decreased left ventricular function, bone pain, emesis, renal failure and prevention of recurrent urinary tract infections, compared to the $3.1 \%(2 / 64)$ in the placebo group due to hepatitis and myocardial infarction. No deaths or serious drug-related events occurred during the study.

The second study was a controlled trial conducted to assess the efficacy and safety of combination mitoxantrone and methylprednisolone in patients with SPMS or worsening RRMS who experienced residual neurological deficit between relapses [66]. At screening, patients were initiated on a two-month protocol consisting of monthly doses of methylprednisolone $1 \mathrm{~g} \mathrm{IV}$, as well as monthly MRI scans. Patients who had developed at least one new gadoliniumenhancing lesion during this time were randomized and included in the study, A total of 42 patients were then randomized to receive either methylprednisolone $1 \mathrm{~g}$ IV monthly or approximately $12 \mathrm{mg} / \mathrm{m}^{2}$ of mitoxantrone IV plus methylprednisolone $1 \mathrm{~g}$ IV for a total of 6 months. All completed the study except five patients in the methylprednisolone group, due to lack of efficacy,

More patients in the mitoxantrone plus methylprednisolone group had no new gadolinium-enhancing lesions at 6 months $(90 \%$ vs $31 \%$; $\mathrm{p}=0.001)$. In addition, the mean EDSS change among the groups was -1.1 and $-0.1(\mathrm{p}=0.013)$, mean annual relapse rate per patient was 0.7 and $3.0(\mathrm{p}=0.003)$ and percentage of patients without relapses was $67 \%$ and $33 \%$ $(\mathrm{p}=0.031)$ for combination and methylprenidolone alone groups, respectively.

The most frequently reported adverse effects reported in the mitoxantrone plus methylprednisolone group, versus the methylprednisolone alone group included amenorrhea, alopecia, nausea, and asthenia. Leukopenia, neutropenia, and mild to moderate infections were also reported at a higher rate in the combination therapy group.

In a multicenter study, the efficacy of mitoxantrone over 24 months was compared to placebo in the proportion of patients with confirmed progression of MS [68]. Fifty-one patients with clinically definite or laboratory-supported RRMS were were randomized to receive either mitoxantrone $8 \mathrm{mg} / \mathrm{m}^{2}$ IV over 30 minutes monthly for 1 year or placebo.

A statistically significant difference in the proportion of patients with confirmed progression of MS as measured by at least one point on the EDSS was seen at 24 months and the total study period (baseline to 24 months) between the treatment and placebo groups $(0 \%$ vs. $25 \%, \mathrm{p}=0.01 ; 7 \%$ vs $37 \%, \mathrm{p}=0.02$ ). No significant differences were noted on the mean change of EDSS scores between the two groups at 12 or 24 months. A significant decrease in the mean number of annual exacerbations was reported when comparing mitaxontrone to placebo at 12 months $(0.52 v s .1 .54, \mathrm{p}=0.001)$ and 
at 24 months $(0.37 \mathrm{vs.} 1.1, \mathrm{p}=0.005)$. The number of exacerbation-free patients were also found to be statistically significant between the groups at 12 months $(70 \%$ vs. $25 \%$, $\mathrm{p}=0.003)$ and at 24 months ( $78 \% v s .42 \%, \mathrm{p}=0.01)$. All 51 patients completed the MRI study except 9 patients due to perceptions of treatment inefficacy, lack of compliance or non-medical reasons. No significant differences in the development of new or enlarged lesions were noted at 12 or 24 months between the two study groups, however, a greater reduction in the number of new lesions was noted in the mitoxantrone group.

The most frequently reported side effects in the mitoxantrone group were mild or moderate nausea, urinary tract and upper respiratory infections, headache, and diarrhea. Five women experienced transient amenorrhea.

\section{Natalizumab}

Natalizumab (Tysabri ${ }^{\circledR}$ ) is the first recombinant humanized monoclonal antibody that was approved by the FDA in November 2004 for use in RRMS (Table 1). It was voluntarily withdrawn from the market by the manufacturer in February 2005 due to 2 reports of progressive multifocal leukoencephalopathy (PML), including one fatal case. In addition, a third patient developed PML in another open label trial involving the use of natalizumab in Crohn's disease [69]. In July 2006, after a thorough review of all patients exposed to this agent and additional clinical trials evaluating its safety and efficacy, the FDA allowed natalizumab to return to the market with a block-box warning of PML and under strict safety restrictions and provisions. This agent is only available to certified practitioners, infusion centers and pharmacies registered through a special restricted distribution program known as the TOUCH ${ }^{\mathrm{TM}}$ (Tysabri ${ }^{\circledR}$ Outreach: Unified Commitment to Health) Prescription Program [69, 70]. Most recently, two European patients were reported to develop PML prompting the FDA to report an alert in August 2008. Natalizumab is currently indicated for monotherapy in the treatment of relapsing forms of MS. It is used to delay the accumulation of physical disability and to reduce the frequency of clinical exacerbations.

Two phase III clinical trials were pivotal in the approval of natalizumab for use in patients with MS. In the first study, 942 patients with a diagnosis of relapsing MS were included $[71,72]$. This was a multicenter, double-blind, placebocontrolled, trial which enrolled patients who had not received INF $\beta$ or glatiramer for the previous 6 months. Eligible patients were randomly assigned (2:1) to receive either natalizumab $300 \mathrm{mg}$ or placebo by IV infusion every 4 weeks for up to 116 weeks.

Results revealed better clinical and MRI endpoints for patients in the natalizumab group at 2 years $(\mathrm{p}<0.001)$. Seventeen percent of the natalizumab group versus $29 \%$ of the placebo group had a sustained increase in disability. There was a relative risk reduction of $42 \%$ at 2 years in the natalizumab group (0.22 vs. 0.67 annual relapse rate). More patients in the natalizumab group remained relapse free at two years $(67 \% v s .41 \%)$.

The most frequently reported serious adverse effects among the natalizumab and placebo groups were infections, acute hypersensitivity reactions, depression, and cholelithiasis. Other adverse events which were significantly more common in the natalizumab group included headache, fatigue, arthralgia, pain in extremity, abdominal discomfort, diarrhea and rash.

The second multicenter, double-blind, placebo-controlled parallel-group trial $[71,73]$ enrolled patients with RRMS (n = 1196), however, only 1171 of these patients were included in data analysis. All patients received treatment with INF $\beta$ 1a for at least 12 months and experienced at least one relapse during the 12-month period prior to study initiation. Patients were randomly assigned to receive either $300 \mathrm{mg}$ of natalizumab or placebo IV every 4 weeks, in addition to $30 \mathrm{mcg}$ of INF $\beta$-1a administered IM once weekly for up to 116 weeks. Combination therapy was reported to have a $24 \%$ reduction in the relative risk of sustained disability $(\mathrm{p}=0.02)$, with a lower cumulative probability of sustained disability progression at two years ( $23 \%$ vs. 29\%; $\mathrm{p}=0.02)$. Combination therapy was also associated with a lower annualized rate of relapse as compared to INF $\beta-1$ a $(0.38 v s .0 .82$ at one year, $\mathrm{p}<0.001 ; 0.34 v s .0 .75$ at two years; $\mathrm{p}<0.001)$. The risk of relapse was reported to be $50 \%$ lower with combination therapy $(\mathrm{p}<0.001) ; 54 \%$ in the combination group and $32 \%$ in the INF 3 -1a group alone $(\mathrm{p}<0.001)$ were relapse-free at two years. In addition, natalizumab produced a $92 \%$ reduction in gadolinium-enhancing lesions $(2.4 v s .0 .2 ; \mathrm{p}<0.001)$, an $83 \%$ reduction in new or enlarging T2-hyperintense lesions (11.0 vs. 1.9; $\mathrm{p}<0.001)$ and a $76 \%$ reduction in new $\mathrm{T} 1-$ hypointense lesions ( 4.6 vs. $1.1 ; \mathrm{p}<0.001$ ) over the two year period.

Commonly reported adverse events of the combination group included anxiety, pharyngitis, sinus congestion and peripheral edema. The incidence of infection was similar in both the combination and INF $\beta-1$ a alone group. The most common serious adverse event among both study groups was MS relapse. Appendicitis was also more common in natalizumab patients. The trial was stopped approximately one month prior to the anticipated date due to 2 cases of natalizumab associated PML.

In another multicenter, double-blind, placebo-controlled trial, a total of 213 patients with clinically definite or laboratory-supported definite RRMS or SPMS were enrolled and included in the intent-to-treat analysis [74]. Patients were randomized to receive either natalizumab $3 \mathrm{mg} / \mathrm{kg}$, natalizu$\mathrm{mab} 6 \mathrm{mg} / \mathrm{kg}$, or placebo administered by IV infusion every 28 days for a total of 6 months. Physical and neurological examinations were performed at monthly, at which time adverse events were also recorded.

Over 6 months, reductions in the number of new lesions in the natalizumab $3 \mathrm{mg} / \mathrm{kg}, 6 \mathrm{mg} / \mathrm{kg}$ and placebo groups were $0.7,1.1$ and 9.6 per patient, respectively)p $<0.001$;). Relapses were seen in 13, 13 and 27 patients respectively, $(\mathrm{p}=0.02)$. The placebo group reported a slight worsening in well-being with a mean decrease of $1.38 \mathrm{~mm}$ (on a $100-\mathrm{mm}$ visualanalogue scale). An improvement in well-being was reported in both the $3 \mathrm{mg} / \mathrm{kg}$ natalizumab and $6 \mathrm{mg} / \mathrm{kg}$ natalizumab groups (a mean increase of $9.49 \mathrm{~mm}$ and $6.21 \mathrm{~mm}$, respectively). The $3 \mathrm{mg} / \mathrm{kg}$ natalizumab group had a mean of 0.7 new gadolinium-enhancing lesions per patient ( $\mathrm{p}<0.001), 1.1$ in the $6 \mathrm{mg} / \mathrm{kg}$ natalizumab group, and 9.6 in the placebo group $(p<0.001)$. No significant difference in values was detected between the two natalizumab groups. 
Subgroup analysis demonstrated the efficacy of natalizumab over placebo in reducing new enhancing lesions in both RRMS and SPMS patients. Natalizumab also caused marked reductions in the numbers of persistent enhancing lesions and new active lesions, the total volume of enhancing lesions, and the percentage of scans showing activity. In addition, fewer natalizumab-treated patients requires corticosteroid treatment for relapses. No significant changes in the EDSS scores were observed in any group during the sixmonth treatment period.

Adverse effects were similar in all groups and included headache, infection, urinary tract infection, accidental injury, pharyngitis, myasthenia, paresthesia, rash, pruritis, back pain, diarrhea and sinusitis. One death due to pleural carcinomatosis complicated by hemothorax was reported in the placebo group.

\section{Comparative Studies}

INF $\beta$-1b has been directly compared to INF $\beta-1$ a $30 \mathrm{mcg}$ IM formulation in patients with RRMS in a multi-center, randomized, 2-year trial (INCOMIN trial), which enrolled 188 patients with RRMS [74]. Significantly more patients receiving IFN $\beta-1 b$ remained relapse-free $(51 \%$ vs. $36 \%)$ and remained free from new MRI lesions (55\% vs. 26\%). It, however, was associated with high level of neutralizing antibodies $(22 \%$ vs. $6 \%$; p < 0.01) [75]. Headache and injection site reactions occurred more frequently in the IFN $\beta-1 b$ treated patients [76]. An open-label Danish study showed no differences in relapses, disease progression or adverse effects between IFN $\beta-1 b$ and IFN $\beta$ - 1 a SC formulation after one year of therapy [77].

A small, single-blinded, randomized, 2-year trial suggested that IFN $\beta-1 \mathrm{~b}$ and both IFN $\beta-1 \mathrm{a}$ formulations provided statistically significant efficacy in RRMS patients [78]. Subcutaneous products, but not intramuscular product, were associated with significant reductions in EDSS. An open label study $(\mathrm{n}=58)$ has suggested that IFN $\beta$-1b was equally effective and tolerated as glatiramer $20 \mathrm{mg}$ daily or every other day [79]. All treatments provided comparable benefits in relapses and EDSS scores. IFN $\beta-1 b$ was associated with a slower progression in disability but glatiramer was better tolerated. Another open label study suggested that INF $\beta-1 b$ and glatiramer, but not INF $\beta-1$ a $\left(\right.$ Avenex $\left.{ }^{\circledR}\right)$ significantly reduced relapse rate [80].

A retrospective, open-label study also suggested glatiramer reduced relapses more than interferons [81]. An open label study showed that delaying therapy with glatiramer increases the risk of neurologic disability in patients with RRMS [81]. When compared to IFN $\beta-1 b$ in an open label study involving RRMS patients, glatiramer was associated with better side effect profile, whereas INF $\beta-1 b$ slowed the progression of disability more significantly [82]. The combination therapy with INF $\beta-1 b$ and glatiramer in the treatment of MS is being explored [83].

\section{DRUGS UNDER DEVELOPMENT}

Cladribine is a purine nucleoside anti-neoplastic agent that is postulated to modulate the T-cell mediated processes in MS [84]. To date, cladribine has been studied in one phase III trial in patients with chronic progressive MS. In the double-blind, randomized, placebo controlled trial, patients started with a 4-week screening phase, followed by one year of a double-blind phase, and then entered into a 6 year extension study. In group 1, patients were given cladribine 0.07 $\mathrm{mg} / \mathrm{kg} /$ day SC for 5 consecutive days for 6 months, followed by 2 months of placebo; in group 2, patients were given cladribine SC $0.07 \mathrm{mg} / \mathrm{kg} /$ day for 5 consecutive days for 2 months, followed by placebo for 6 months; in group 3, patients were given placebo for 8 months. At the end of the treatment phase, the cladribine groups did not differ from the placebo group in terms of disability scores, but did show fewer gadolinium-enhancing lesions on MRI. At the end of the study, the proportion of patients with gadoliniumenhancing lesions decreased by $70 \%$ in the group 1 , and by $83 \%$ in group 2, as compared to $18 \%$ in the placebo group. Treatment-related adverse events included muscle weakness, hypertonia, purpura, rhinitis, ataxia, and upper respiratory tract infection.

Fingolimod is a sphingosine-1-phosphate (S1P) receptor agonist which causes down-regulation of the S1P receptor, leading to sequestration of T-cells in the thymus and secondary lymphoid organs [85]. Suppressing the migration of Tcells can help reduce the autoimmune activity in MS. Fingolimod has been evaluated in the treatment of RRMS in one phase II trial [86]. In the double-blind, placebo-controlled study, 281 patients received oral regimens of either fingolimod $1.25 \mathrm{mg}, 5 \mathrm{mg}$ or placebo once daily for 6 months. In the extension phase of the study, patients receiving placebo were crossed over to receive fingolimod at $1.25 \mathrm{mg}$ or $5 \mathrm{mg}$ daily for 6 months. Patients initially receiving fingolimod continued the drug at the same dose for another 6 months. At the end of the first 6 months, the number of gadoliniumenhanced lesions was lower in the fingolimod $1.25 \mathrm{mg}$ and 5 $\mathrm{mg}$ groups than in the placebo group $(8.4,5.7$, and 14.8 lesions, respectively; $\mathrm{p}<0.001)$. At the end of 12 months, the number of gadolinium-enhanced lesions was similar in patients who received placebo followed by fingolimod as in patients who had received fingolimod for the entire 12 months. Adverse event occurring commonly in the fingolimod patients included nasopharyngitis, dyspepsia, headache, somnolence, diarrhea, and nausea. Elevations in alanine transaminase were seen in the fingolimod $1.25 \mathrm{mg}$ and $5 \mathrm{mg}$ group. A phase III study is currently underway [87].

\section{CONCLUSION}

MS continues to be a complex and devastating disease. Many questions still exist regarding its etiology and pathophysiology, making an appropriate approach to treatment challenging. A few disease modifying agents are available. While interferon beta $1 \mathrm{a}$ and $1 \mathrm{~b}$ have relatively long-term clinical experience in patients with RRMS, the beta $1 \mathrm{~b}$ formulation recently demonstrated its effect in delaying the time to diagnosis of definite MS. Glatiramer and natalizumab have both established efficacy in relapsing forms of multiple sclerosis; whereas mitoxantrone is more commonly used in patients with advanced disease. Although all disease modifying agents reduce MS relapses by interacting with the immunologic system, each of them have side effects that requires specific clinical monitoring. More data on comparative efficacy and long term information on safety are eagerly awaited. The effects of investigational compounds are also greatly anticipated, and may provide hopes of addressing the 
challenges in reducing or delaying the distressing MS-related health concerns.

\section{REFERENCES}

[1] Holland NJ. Overview of multiple sclerosis. National Multiple Sclerosis Society. Available at: http: //www.nationalmssociety.org/ docs/HOM/BasicFacts.pdf [Accessed: January 20, 2008].

[2] Noseworthy JH, Lucchinetti C, Rodriguez M, et al. Multiple sclerosis. N Engl J Med 2000; 343: 938-52.

[3] Anderson DW, Ellenberg JH, Leventhal CM, et al. Revised estimate of the prevalence of multiple sclerosis in the United States. Ann Neurol 1992; 31: 333-6.

[4] Ebers GC. Genetics and multiple sclerosis: an overview. Ann Neurol 1994; 36: S12-S14.

[5] Compston A. The epidemiology of multiple sclerosis: principles, achievements, and recommendations. Ann Neurol 1994; 36: S211S217.

[6] Sadovnick AD, Baird PA, Ward RH. Multiple sclerosis: updated risks for relatives. Am J Med Genet 1988; 29: 533-41.

[7] Willer CJ, Dyment DA, Risch NJ, et al. Twin concordance and sibling recurrence rates in multiple sclerosis. Proc Natl Acad Sci USA 2003; 100: 12877-82.

[8] Sadovnick AD, Ebers GC, Wilson RW, et al. Life expectancy in patients attending multiple sclerosis clinics. Neurology 1992; 42: 991-4.

[9] Guthrie EW. Overview of multiple sclerosis. US Pharm 2005; 30 : 73-82.

[10] Berti R, Soldan SS, Akhyani N, et al. Extended observations on the association of HHV-6 and multiple sclerosis. J Neurovirol 2000; 6: S85-S87.

[11] Johnson RT. The virology of demyelinating diseases. Ann Neurol 1994; 36: S54-S60.

[12] Swanborg RH, Whittum-Hudson JA, Hudson AP. Infectious agents and multiple sclerosis-are Chlamydia pneumoniae and human herpes virus 6 involved? J Neuroimmunol 2003; 136: 1-8.

[13] Marrie RA. Environmental risk factors in multiple sclerosis aetiology. Lancet Neurol 2004; 3: 709-18.

[14] Detels R, Visscher BR, Haile RW, et al. Multiple sclerosis and age at migration. Am J Epidemiol 1978; 108: 386-93.

[15] Burks JS, Arnason BG, Coyle PK, et al. Issues and practices in multiple sclerosis. Neurorehabil Neural Repair 2002; 16: 1-14.

[16] Weinshenker BG. The natural history of multiple sclerosis. Neurol Clin 1995; 119: 119-46.

[17] Polman $\mathrm{CH}$, Uitdehaag BMJ. Drug treatment of multiple sclerosis. BMJ 2000; 321: 490-4.

[18] Weinshenker GC, Bass B, Rice GPA, et al. The natural history of multiple sclerosis: a geographically based study, I: clinical course and disability. Brain 1989; 112: 133-46.

[19] Neuhaus O, Kieseier BC, Hartung HP. Therapeutic role of mitoxantrone in multiple sclerosis. Pharmacol Ther 2006; 109: 198209.

[20] Lublin FD, Reingold SC. Defining the course of multiple sclerosis: results of an international survey. Neurology 1996; 46: 907-11.

[21] Andersson PB, Waubant E, Gee L, Goodkin DE. Multiple sclerosis that is progressive from the time of onset. Arch Neurol 1999; 56: $1138-46$.

[22] Scott TF, Schramke CJ, Novero J, Chieffe C. Short-term prognosis in early relapsing-remitting multiple sclerosis. Neurology 2000; 55: 689-93.

[23] Kantarei O, Siva A, Eraksoy M, et al. Survival and predictors of disability in Turkish MS patients. Neurology 1998; 51: 765-72.

[24] McDonald WI, Compston A, Edan G, et al. Recommended diagnostic criteria for multiple sclerosis: guidelines from the international panel on the diagnosis of multiple sclerosis. Ann Neurol 2001; 50: 121-7.

[25] National Collaborating Centre for Chronic Conditions. Multiple sclerosis. National clinical guideline for diagnosis and management in primary and secondary care. London (UK): National Institute for Clinical Excellence (NICE) 2004.

[26] Filippi M, Horsfield MA, Ader HJ, et al. Guidelines for using quantitative measures of brain magnetic resonance imaging abnormalities in monitoring the treatment of multiple sclerosis. Ann Neurol 1998; 43: 499-506.
[27] Polman CH, Reingold SC, Edan G, et al. Diagnostic criteria for multiple sclerosis: 2005 revisions to the "McDonald Criteria." Ann Neurol 2005; 58: 840-6.

[28] Markowitz CE. Interferon-beta: mechanism of action and dosing issues. Neurology 2007; 68: S8-S11.

[29] Tourbah A, Lyon-Caen. Interferons in multiple sclerosis: ten years experience. Biochimie 2007; 89: 899-902.

[30] Jacobs LD, Cookfair DL, Rudick RA, et al. Intramuscular interferon beta-1a for disease progression in relapsing multiple sclerosis. Ann Neurol 1996; 39: 285-94.

[31] Jacobs LD, Beck RW, Simon JH, et al. Intramuscular interferon beta-1a therapy initiated during a first demyelinating event in multiple sclerosis. N Engl J Med 2000; 343(13): 898-904.

[32] PRISMS (Prevention of Relapses and Disability by Interferon $\beta-1 \mathrm{a}$ Subcutaneously in Multiple Sclerosis) Study Group. Randomized double-blind placebo-controlled study of interferon $\beta-1 \mathrm{a}$ in relapsing/remitting multiple sclerosis. Lancet 1998; 352: 1498-504.

[33] PRISMS (Prevention of Relapses and Disability by Interferon $\beta-1 \mathrm{a}$ Subcutaneously in Multiple Sclerosis) Study Group. PRISMS-4: long-term efficacy of interferon $\beta$-1a in relapsing MS. Neurology 2001; 56: 1628-36.

[34] Panitch H, Goodin DS, Francis G, et al. Randomized, comparative study of interferon $\beta$-1a treatment regimens in MS: the EVIDENCE trial. Neurology 2002; 59: 1496-506.

[35] Schwid SR, Sharief M, Sandberg-Wollheim M, et al. Enhanced benefit of increasing interferon beta-1a dose and frequency in relapsing multiple sclerosis: the EVIDENCE study. Arch Neurol 2005; 62: 785-692.

[36] Avonex Prescribing Information (interferon $\beta$-1a). Biogen Idec, Inc. Cambridge, MA, November 2006.

[37] Rebif Prescribing Information (interferon $\beta$-1a). Serono, Inc. Rockland, MA, September 2005.

[38] Rothuizen LE, Buclin T, Spertini F, et al. Influence of interferon beta-1a dose frequency on PBMC cytokine secretion and biological effect markers. J Neuroimmunol 1999; 99: 131-41.

[39] Betaseron ${ }^{\circledR}$ Prescribing Information. Bayer HealthCare Pharmaceuticals Inc. Montville, New Jersey, USA. September 2007.

[40] The IFNB Multiple Sclerosis Study Group. Interferon beta- $1 \mathrm{~b}$ is effective in relapsing-remitting multiple sclerosis. I. Clinical results of a multicenter, randomized, double-blind, placebo-controlled trial. Neurology 1993; 43: 655-61.

[41] Paty DW, Li DK. Interferon beta- $1 \mathrm{~b}$ is effective in relapsingremitting multiple sclerosis. II. MRI analysis results of a multicenter, randomized, double-blind, placebo-controlled trial. UBC MS/MRI Study Group and the IFNB Multiple Sclerosis Study Group. Neurology 1993; 43: 662-7.

[42] Interferon beta- $1 \mathrm{~b}$ in the treatment of multiple sclerosis: final outcome of the randomized controlled trial. The IFNB Multiple Sclerosis Study Group and The University of British Columbia MS/MRI Analysis Group. Neurology 1995; 45: 1277-85.

[43] Kappos L, Polman CH, Freedman MS, et al. Treatment with interferon beta- $1 \mathrm{~b}$ delays conversion to clinically definite and McDonald MS in patients with clinically isolated syndromes. Neurology 2006; 67: 1242-9.

[44] European Study Group on interferon beta-1b in secondary progressive MS. Placebo-controlled multicentre randomised trial of interferon beta- $1 \mathrm{~b}$ in treatment of secondary progressive multiple sclerosis. Lancet 1998; 352: 1491-7.

[45] Panitch H, Miller A, Paty D, Weinshenker B. Interferon beta-1b in secondary progressive MS: results from a 3-year controlled study. Neurology 2004; 63: 1788-95.

[46] Coyle PK. Evidence-based medicine and clinical trials. Neurology 2007; 68: S3-7.

[47] Kappos L, Weinshenker B, Pozzilli C, et al. Interferon beta-1b in secondary progressive MS: a combined analysis of the two trials. Neurology 2004; 63: 1779-87.

[48] Noronha A. Neutralizing antibodies to interferon. Neurology 2007; 69: S16-S22.

[49] Gneiss C, Tripp P, Reichartseder F, et al. Differing immunogenic potentials of interferon beta preparations in multiple sclerosis patients. Mult Scler 2006; 12: 731-7.

[50] Gneiss C, Reindl M, Lutterotti A, et al. Interferon-beta: the neutralizing antibody $(\mathrm{NAb})$ titre predicts revision to NAb negativity. Mult Scler 2004; 10: 507-510.

[51] Tremlett HL, Yoshida EM, Oger J. Liver injury associated with the $\beta$-interferons for MS. Neurology 2004; 62: 628-31. 
[52] Copaxone ${ }^{\circledR}$ Prescribing Information. Aventis Pharmaceuticals Inc. Kansas City, MO, 2004

[53] Wolinsky JS, Narayana PA, Johnson KP. United States open-label glatiramer acetate extension trial for relapsing multiple sclerosis: MRI and clinical correlates. Multiple Sclerosis Study Group and the MRI Analysis Center. Mult Scler 2001; 7: 33-41.

[54] Bornstein MB, Miller A, Slagle S, et al. A pilot trial of Cop 1 in exacerbating-remitting multiple sclerosis. N Engl J Med 1987; 317(7): 408-14.

[55] Johnson KP, Brooks BR, Cohen JA, et al. Copolymer 1 reduces relapse rate and improves disability in relapsing-remitting multiple sclerosis: results of phase III multicenter, double-blind placebocontrolled trial. The Copolymer 1 MS study Group. Neurology 1995; 45(7): 1268-76.

[56] Johnson KP, Brooks BR, Cohen JA, et al. Extended use of glatiramer acetate (Copaxone) is well tolerated and maintains its clinical effect on multiple sclerosis relapse rate and degree of disability. Copolymer 1 Multiple Sclerosis Study Group. Neurology 1998; 50: 701-8.

[57] Ford CC, Johnson KP, Lisak RP, et al. A prospective open-label study of glatiramer acetate: over a decade of continuous use in multiple sclerosis patients. Mult Scler 2006; 12(3): 309-20.

[58] Pöllmann W, Erasmus L, Feneberg W, Then Bergh F, Straube A. Interferon beta but not glatiramer acetate therapy aggravates headaches in MS. Neurology 2002; 59: 636-9.

[59] Pöllmann W, Erasmus L, Feneberg W, Straube A. The effect of glatiramer acetate treatment on pre-existing headaches in patients with MS. Neurology 2006; 66: 275-7.

[60] Comi G, Filippi M, Wolinsky JS. European/Canadian multicenter, double-blind, randomized, placebo-controlled study of the effects of glatiramer acetate on magnetic resonance imaging--measured disease activity and burden in patients with relapsing multiple sclerosis. European/Canadian Glatiramer Acetate Study Group. Ann Neurol 2001; 49: 290-7.

[61] Filippi M, Rovaris M, Rocca MA, Sormani MP, Wolinsky JS, Comi G. Glatiramer acetate reduces the proportion of new MS lesions evolving into "black holes". Neurology 2001; 57: 731-3.

[62] Ramtahal J, Jacob A, Das K, Boggild M. Sequential maintenance treatment with glatiramer acetate after mitoxantrone is safe and can limit exposure to immunosuppression in very active, relapsing remitting multiple sclerosis. J Neurol 2006; 253: 1160-4.

[63] Zwibel HL. Glatiramer acetate in treatment-naïve and prior interferon-beta-1b-treated multiple sclerosis patients. Acta Neurol Scand 2006; 113: 378-86.

[64] Vallittu AM, Peltoniemi J, Elovaara I, et al. The efficacy of glatiramer acetate in beta-interferon-intolerant MS patients. Acta Neurol Scand 2005; 112: 234-7.

[65] Wolinsky JS, Narayana PA, O'Connor P, et al. Glatiramer acetate in primary progressive multiple sclerosis: results of a multinational, multicenter, double-blind, placebo-controlled trial. Ann Neurol 2007; 61: 14-24.

[66] Mitoxantrone (Novantrone ${ }^{\circledR}$ ), package insert. Rockland, MA: Serono, Inc.; April 2005.

[67] Hartung HP, Gonsette R, Konig N, et al. Mitoxantrone in progressive multiple sclerosis: a placebo-controlled, double-blind, randomized, multicentre trial. Lancet 2002; 360: 2018-25.

[68] Millefiorini E, Gasperini C, Pozzilli C, et al. Randomized placebocontrolled trial of mitoxantrone in relapsing-remitting multiple sclerosis: 24-month clinical and MRI outcome. J Neurol 1997; 244: 153-9.

[69] Healthcare professional letter: Important drug warning. July 2006. Available at: http: //www.fda.gov/medwatch/safety/2006/tysabri DHCPL.pdf [Accessed: January 23, 2008].
[70] Johnson KP. Natalizumab (Tysabri) treatment for relapsing multiple sclerosis. The Neurologist 2007; 13: 182-7.

[71] Natalizumab (Tysabri ${ }^{\circledR}$ ), package insert. Cambridge, MA: Biogen Idec, Inc.; January 2008.

[72] Polman CH, O'Connor PW, Havrdove E, et al. A randomized, placebo-controlled trial of natalizumab for relapsing multiple sclerosis. N Engl J Med 2006; 354: 899-910.

[73] Rudick RA, Stuart WH, Calabresi PA, et al. Natalizumab plus interferon beta-1a for relapsing multiple sclerosis. N Engl J Med 2006; 354: 911-23.

[74] Miller DH, Khan OA, Sheremata WA, et al. A controlled trial of natalizumab for relapsing multiple sclerosis. N Engl J Med 2003; 348: 15-23.

[75] Durelli L, Verdun E, Barbero P, et al. Every-other-day interferon beta- $1 \mathrm{~b}$ versus once-weekly interferon beta-1a for multiple sclerosis: results of a 2-year prospective randomised multicentre study (INCOMIN). Lancet 2002; 359: 1453-60.

[76] Barbero P, Bergui M, Versino E, et al. Every-other-day interferon beta- $1 \mathrm{~b}$ versus once-weekly interferon beta- $1 \mathrm{a}$ for multiple sclerosis (INCOMIN Trial) II: analysis of MRI responses to treatment and correlation with Nab. Mult Scler 2006; 12: 72-6.

[77] Koch-Henriksen N, Sørensen PS, Christensen T, et al. A randomized study of two interferon-beta treatments in relapsing-remitting multiple sclerosis. Neurology 2006; 66: 1056-60.

[78] Etemadifar M, Janghorbani M, Shaygannejad V. Comparison of Betaferon, Avonex, and Rebif in treatment of relapsing-remitting multiple sclerosis. Acta Neurol Scand 2006; 113: 283-7.

[79] Flechter S, Vardi J, Pollak L, Rabey JM. Comparison of glatiramer acetate (Copaxone) and interferon beta-1b (Betaferon) in multiple sclerosis patients: an open-label 2-year follow-up. J Neurol Sci 2002; 197: 51-5.

[80] Khan OA, Tselis AC, Kamholz JA, Garbern JY, Lewis RA, Lisak RP. A prospective, open-label treatment trial to compare the effect of IFNbeta-1a (Avonex), IFNbeta-1b (Betaseron), and glatiramer acetate (Copaxone) on the relapse rate in relapsing--remitting multiple sclerosis: results after 18 months of therapy. Mult Scler 2001; 7: 349-53.

[81] Haas J, Firzlaff M. Twenty-four-month comparison of immunomodulatory treatments - a retrospective open label study in 308 RRMS patients treated with beta interferons or glatiramer acetate (Copaxone). Eur J Neurol 2005; 12: 425-31.

[82] Flechter S, Kott E, Steiner-Birmanns B, Nisipeanu P, Korczyn AD. Copolymer 1 (glatiramer acetate) in relapsing forms of multiple sclerosis: open multicenter study of alternate-day administration. Clin Neuropharmacol 2002; 25: 11-5.

[83] Ytterberg C, Johansson S, Andersson M, et al. Combination therapy with interferon-beta and glatiramer acetate in multiple sclerosis. Acta Neurol Scand 2007; 116: 96-9.

[84] Brousil JA, Roberts RJ, Schlein AL. Cladribine: an investigational immunomodulatory agent for multiple sclerosis. Ann Pharmacother 2006; 40: 1813-21

[85] Brown BA, Kantesaria PP, McDevitt L. Fingolimod: a novel immunosuppressant for multiple sclerosis. Ann Pharmacother 2007; 41: $1660-8$

[86] Kappos L, Antel J. Comi G, et al. Oral fingolimod (FTY720) for relapsing multiple sclerosis. New Engl J Med 2006; 355: 1124-40.

[87] Efficacy and Safety of Fingolimod in Patients With RelapsingRemitting Multiple Sclerosis (FREEDOMS). Available from: http: //clinicaltrials.gov/ct2/show/NCT00289978 [Accessed: 23 January 2008].

(c) Hilas et al.; Licensee Bentham Open.

This is an open access article licensed under the terms of the Creative Commons Attribution Non-Commercial License (http://creativecommons.org/licenses/by-nc/3.0/) which permits unrestricted, non-commercial use, distribution and reproduction in any medium, provided the work is properly cited. 